\title{
Michel Brix, Sade et les félons
}

\author{
Irene Panighetti
}

\section{(2) OpenEdition}

\section{Journals}

\section{Edizione digitale}

URL: https://journals.openedition.org/studifrancesi/37801

DOI: 10.4000/studifrancesi.37801

ISSN: 2427-5856

\section{Editore}

Rosenberg \& Sellier

\section{Edizione cartacea}

Data di pubblicazione: 15 décembre 2004

Paginazione: 618-619

ISSN: 0039-2944

\section{Notizia bibliografica digitale}

Irene Panighetti, «Michel Brix, Sade et les félons», Studi Francesi [Online], 144 (XLVIII | III) | 2004, online dal 30 novembre 2015, consultato il 08 mai 2021. URL: http://journals.openedition.org/studifrancesi/ 37801 ; DOI: https://doi.org/10.4000/studifrancesi.37801

\section{Questo documento è stato generato automaticamente il 8 mai 2021.}

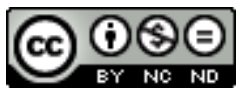

Studi Francesi è distribuita con Licenza Creative Commons Attribuzione - Non commerciale - Non opere derivate 4.0 Internazionale. 


\title{
Michel Brix, Sade et les félons
}

\author{
Irene Panighetti
}

\section{NOTIZIA}

MICHEL BRIX, Sade et les félons, Jaignes, La Chasse au Snark («Critique»), 2003, pp. 314.

1 Con questo volume Michel Brix si ripropone di svelare «la doppia impostura dell'ideologia libertina», fondata su due postulati essenziali: il primo che il piacere dell'appagamento sessuale è un dono di Dio, quindi legittimo e buono; il secondo che le donne sono uguali agli uomini nelle dinamiche della seduzione e dell'erotismo. Per riuscire nel suo intento l'autore comincia col delineare il ritratto del libertino settecentesco: un personaggio che mette in pratica la lezione del libertinaggio intellettuale del Seicento, collegandola all'insegnamento dei Philosophes, con il risultato di mettere in discussione dei valori tradizionali e della costante riflessione sul proprio pensiero e sul proprio modo di agire. Quindi Michel Brix propone una sua definizione dei romans libertins: testi che si prefiggono di mettere in evidenza l'ambiguità dell'ideologia libertina, mostrandone l'estrema pericolosità attraverso personaggi meschini e deprecabili.

2 Dopo queste precisazioni preliminari l'autore passa ad esaminare le opere di Casanova e di Sade, due scrittori che la critica ha considerato ai margini dell'ideale libertino ma che, secondo Michel Brix, appartengono invece a pieno titolo al contesto del libertinaggio settecentesco.

3 Casanova è stato giudicato come un personaggio dalla sensualità euforica ma priva di ogni perversità e di ogni volontà di dominio. Michel Brix, analizzando l'Histoire de ma vie del veneziano, dimostra, al contrario, che egli presenta tutti i tratti del libertino: misogino, narcisista, truffatore, vanesio, addirittura incestuoso convinto. Egli "fut bien un libertino. Pis: de tous les libertins, il fut sans contexte le plus diabolique”.

4 Per il marchese de Sade il discorso è più complesso e articolato, e per questo Michel Brix gli dedica uno studio più ampio e più approfondito rispetto a Casanova. Brix inizia analizzando le interpretazioni dell'opera di Sade, da quelle settecentesche fino alle più 
recenti, e mette in discussione soprattutto due concetti dominanti della tradizione critica: l'idea, propriamente novecentesca, che Sade sia stato l'apologeta del libertinaggio assoluto, e la convinzione che la natura perversa del marchese sia stata rafforzata dalla prigionia. Rispetto al primo concetto, Brix ritiene che i testi di Sade non siano un'esaltazione del libertinaggio, bensì, paradossalmente, una sua stroncatura, poiché, mostrando crudamente le abominevoli conseguenze della vita libertina, spaventano a tal punto il lettore, da indirizzarlo verso la retta morale. Riguardo al secondo punto, egli sostiene che la prigione, lungi dall'incoraggiare le perversioni del marchese, avrebbe suscitato in lui una riflessione critica sul suo passato, sollecitandolo a scrivere le sue memorie, trasposte e sublimate nella letteratura, come esempio negativo non da emulare, ma da respingere con orrore.

5 Per argomentare le sue tesi Brix analizza dettagliatamente tutti gli scritti di Sade, mettendone in luce le caratteristiche specifiche e gli stretti rapporti che li legano alle opere dei Philosophes e dimostrando che tra queste ultime e i testi del marchese si instaura una retorica della citazione più o meno esplicita, che testimonia l'atteggiamento sottilmente ironico di Sade nei confronti delle idee illuministe. Questo permette a Brix di sostenere che Sade è stato "la face cachée des Lumières", il rovescio tenebroso e inquietante della solare e rassicurante ideologia illuminista. Le opere di Sade non sono quindi lette come l'apologia del libertinaggio, bensì come una feroce, seppur implicita, denuncia di una delle "plaies de la société française des Lumières". 